\section{SCIENCE AND RECONSTRUCTION*}

\author{
BY THE RIGHT HON. SIR JOHN ANDERSON, \\ G.C.B., G.C.S.I., G.C.I.E., F.R.S., M.P.
}

$\mathrm{M}^{\mathrm{Y}}$ $Y$ interest in science dates back to the early years of this century when, having secured a scholarship of sufficient value to enable me to devote a year or two to further study abroad, I went to Germany to engage in postgraduate research in physical chemistry. As it happens, the subject allotted to $\mathrm{me}$ was an investigation of the radioactive properties of uranium, a curious coincidence in view of certain activities in which I have recently been engaged.

I had previously, while still an undergraduate in Edinburgh, become somewhat concerned about the economic prospects for specialists in natural seience. I had noticed, for example, that, apart from schoolmastering and the limited establishments of the science departments of the universities, there seemed to be no demand in Britain for chemists. Things indeed were still much as Lavoisier found them when, having been condemned to death and being disposed to protest, he was informed coldly that the world had no need for chemists. The War Office assessment of the value of trained chemists was expressed in 1905 in the offer of a commencing salary of $£ 130$ a year. The only industrial openings one heard of were occasional vacancies in breweries, and those usually went to well-trained specialists from Denmark. The fact is that, at that time, the staple industries of Britain still relied on the traditional methods which had served them well before international competition became acute. I well remermber learning from a schoolfellow the horror with which his father, the proprietor of a famous tannery, had received the suggestion that he should introduce a few trained chemists into his tanyard.

However, youth is generally optimistic, and it was not until $I$ had been at work for some time and found that my researches were proceeding rather slowly-as was bound to be the case from what we now know of the nature of the subject-that my mind began to dwell again on the prosaic question of earning one's living. On reflexion, it was borne in upon me that, while my research work was subject to no time factor, I was approaching the age limit for entry into the Higher Division of the Civil Service. I decided that I had better try for that before it was too late, and thus have no occasion to regret having missed an opportunity that would never recur. In the result, I was awarded a position as a "2nd Class Clerk in the Colonial Office"-such was the unimaginative and even repellent terminology then in vogue and the whole tenor of my life was changed.

This fragment of autobiography enables me to bring out two facts that are not without interest in relation to the subject of my address. The first is that a good grounding in natural science can be a passport to the higher Civil Service, equally with the more usual training in the humanities, or in the history schools. The second, as exemplified in my own case, is that public administration does provide scope, apart from the professional or specialist grades, for men with a scientific training. For example, at the beginning of the War of 1914-18, we were confronted with a serious situation owing to the sudden cutting off of all supplies of those synthetic

* Address before the Manchester Joint Research Coumcil at Manhester delivered on December 6 . drugs and other fine chemicals and dyestuffs for which we had allowed ourselves to become entirely dependent on Germany. I was made responsible for organizing measures for making good the deficiency so far as the medicinal requirements of the country were concerned, and I was also in continuous consultation with those who were dealing with the explosives and dyestuffs situation. It would take too long to describe the nature of the action that was taken-and taken successfully-to overcome what might have been a fatal handicap in that conflict, but I certainly could not have played my part had it not been for my earlier training. Much more recently that training has again stood $\mathrm{me}$ in good stead in discharging the responsibilities that fell to me as Lord President of the Council, leading up to the work on atomic energy to which I am still giving part of my time.

After this rather lengthy introduction, I come to my main subject-science in relation to reconstruction. The restoration of the economic life of Britain, and even the maintenance of the living standards established pre-war, is dependent on building up our industries to a level of efficiency higher than ever before attained. We have, to a large extent, lost the competitive advantage which our mineral resources and sea-power gave us in the halcyon days of last century. It is a further disadvantage that the exports which we must have in order to pay for vital supplies of food and raw materials are so much greater in relation to the corresponding home demand than in the case of either the United States or the U.S.S.R. It is on the quality of our products that we must rely to overcome all disadvantages, and to this end we must build up the finest possible bodies of tech. nicians and make the fullest use of all new developments to which science can point the way. There is no reason to doubt our ability to do this if we know where the obstacles are and show a determination to remove them.

It has long been the fashion to decry our achievements in the field of applied science in the past, though in pure science they are, of course, universally recognized to have been outstanding. This has, no doubt, been in part a pose, exemplifying our wellknown habit of self-depreciation. But, in my view, we have, in fact, lagged behind, and for two main reasons - partly because of the dead hand of tradition in our older industries and partly because of prejudice on the part of scientific men themselves. The profit motive was suspect in the higher academic circles before it became an object of attack in politics. The author of one of the most fundamental, and, as it turned out, most fruitful discoveries in electrical science plumed himself on the fact that it could be of no possible use. We must get rid, and we are getting rid, of all that nonsense so far as scientific workers are concerned.

I have said that we have lagged behind in the past ; but things were never so bad as is sometimes made out. It is true that, apart from certain traditional lines such as acid and alkali production, chloroform, a few alkaloids and a very narrow range of dyestuffs such as alizarin (turkey red) and azo dyes (khaki) we had no chemical industry at the outbreak of the War of 1914-18. But, as I have already indicated, much was done during that War to overcome the initial handicap, and what has been achieved sinceup to the outbreak of the recent War and during its progress-is full of encouragement. That was only to be expected in the case of the great new electrical 
and chemical industries which had their foundations in scientific discoveries; but the older industries can also show many notable instances of a fresh outlook. Let me give a few illustrations in both categories.

In the textile industries, before the War, both uncreasable cotton and unshrinkable wool had been produced as a result of prolonged researches and, during the War, cotton fabrics have been produced in large quantity in which the fibres are so twisted that, on contact with water, they immediately swell and render the cloth waterproof, while at the same time allowing the passage of air.

In the steel and non-ferrous metal industries new processes have been developed and new materials produced for the first time, including many types of alloy steel, and great quantities of magnesium metal from sea-water.

In television we undoubtedly led the world before the War and we are probably still ahead. In the various applications of radio-location, founded upon investigations originally conducted under the Radio Research Board of the Department of Scientific and Industrial Research, we were in almost every instance well ahead of all competitors. Here is a magnificent example of co-operation between science and industry, resulting in the production of power valves working on wave-lengths of a few centimetres-a development undreamt of a few years before.

Between the Wars, Britain gained all the speed. records in the air, on water and on land, with British pilots and British machines made in British workshops. We now hold all these records again.

All aeroplanes are fitted with perspex-the transparent non-splintering plastic produced in Britainand, during the War, our chemical industry produced also polythene-the finest insulator knownwithout which some of the most important applications of radio-location would have been impossible.

An insecticide (gammexane) probably more efficient than D.D.T., a range of selective weedkillers, linked with the discovery of the hormones produced in the growing tips of plants-which may well mean a revolution in agricultural methods-a synthetic adhesive, heat-, water-and acid-proof, giving unions stronger than those obtained by riveting or spot welding, are other achievements of our progressive and virile chemical industry.

The 'Mosquito', produced straight from the drawing board, largely by coach-building and furniture factories, and made operational in the record period of twenty-two months, could carry the same weight of bombs to Berlin as a 'Flying Fortress', with a crew of two instead of ten, and at 100 miles an hour faster. The British-made 'ILancaster' carried the biggest bomb-load and was the only aircraft capable of carrying the 10-ton bomb. Between 1939 and 1944 the Merlin engine was doubled in horse-power and performance, without any increase in weight, and we have recently read with pride what they think of it in the United States.

In the manufacture of scientific instruments, where during the First World War we found ourselves sadly behind, there is the same story of technical skill and successfully applied research. Our bomb-sights and predictors, containing incredibly delicate and complicated mechanism, were nevertheless robust enough to be carried in our bombers, and simple enough in operation to be used by technically unqualified personnel.

The measures to combat the magnetic mineperhaps our greatest anxiety in the early months of the War-the prefabricated breakwaters and harbours known as "Gooseberry" and "Mulberry", and the submarine pipelines for carrying petrol to the Continent, are other outstanding examples of tech. nical achievement.

The illustrations, which I could multiply many times over in respect of a wide range of activities, show the high technical efficiency of British industries and their readiness to appreciate and develop new ideas born in our research laboratories. I give them now merely in order to establish my contention that the prognosis in this matter of the application of science in industry during the period of reconstruction is extremely favourable.

If that is accepted, let us look a little farther to see what is still needed in order to make the most of our resources, actual and potential, and of our opportunities. This is the kernel of our problem, and I will deal with it under the three heads of : (1) personnel, (2) finance and (3) organization.

Personnel. Sir Ermest Simon has directed attention to the discrepancy between the numbers of scientific. ally trained personnel turned out by the universities and other teaching establishments in the United States and Great Britain respectively. Allowing, as of course one must, for the difference in total population, we come very badly indeed out of the comparison. No doubt we make up to some extent in quality for lack of numbers; but the fact seems indisputable that the output has, in the past, been far below what the real needs of the country demand.

Clearly the deficiency, whatever it may be-and some further investigations seem called for under that head-cannot be made good all at once. The first step must be to enlarge the capacity of our teaching institutions, to get more scientific men of high quality back from war service to the teaching staffs of the universities, and then further to expand their numbers in the appropriate branches and perhaps to extend classroom and laboratory accommodation. This will require some order of priority, and $\mathrm{I}$ have little doubt that Mr. Morrison was right when he said recently that the needs of industry must at first give way to some extent before those of the universities. Then the necessary steps must be taken to increase the flow of students-not just any sort of students, but students of the right typo-with the best kind of general educational background. Some propaganda will be needed here. I, personally, thought it unfortunate that so little was made of the importance of scientific and technical education during the passage of the Education Bill last year. I think a great opportunity was lost; but no harm may result in the long run if we do now what is urgently needed, and that is to prepare the best possible estimatequantitative and qualitative- of future requirements. Universities, industrial firms and all other potential employers, including the Government, should make, and make known, their plans, indicating the types and numbers of trained men and women they require, the terms they offer and the kind of organization they propose. Such information, properly collated, will be an indispensable basis for the work of the committee on scientific priorities which Mr. Morrison recently announced in Parliament, and will also provide the necessary material for an approach to headmasters and, through them, to parents. As a first step one cannot go wrong in urging that everything possible should be done to hasten the release of trained scientific workers and of partly trained and 
untrained students from the various forms of war service.

Finance. I come now to a matter which I would rank as high in importance as that of personnelfinance. Here I may modestly claim to have myself blazed a trail. Broadly speaking, research and development must be financed in one or more of the following ways : by industrialists, either in their own laboratories or through industrial research associations, or through grants to universities ard other scientific institutions; by universities and other scientific institutions out of their own resources; by Government, through research institutions of its own, or through grants to industrial research associations, to individual workers or to universities.

While I was still Lord President, the basis of grants to research associations was reviewed by the Advisory Council of the Department of Scientific and Industrial Research, under Lord Riverdale, and now arrangements have been made which represent a very substantial improvement on the old. Whereas the Department used to work on the principle that a Government grant would be available only until the association could be made self-supporting, the principle of a permanent grant is now accepted, and the basis of calculation has been liberalized. This marks a fundamental change in outlook. Government grants to universities are made through, and on the recommendation of, the University Grants Com. mittee, which has been reconstituted to bring it into closer touch with the universities. About a year ago, I met the Committee of Vice-Chancellors and foreshadowed a substantially increased rate of grant which has now been voted by Parliament for the current year. In addressing them, I referred, in particular, to the need for a revision of university salaries, and I made it clear that, for the first time this year and in future, capital expenditure would be taken into account in assessing grants. It is left to each university to allocate its grant as it thinks fit, subject, of course, to any general understanding between that university and the Committee. Grants earmarked for specific researches are made not by the Committee but by the Department of Scientific and Industrial Research, with the approval of the Treasury. The Department also administers a scheme of maintenance grants for postgraduate students to allow them to be trained in methods of research.

Expenditure by industrialists is assisted not by direct grant but by a system of tax relief. Up to this year, maintenance expenditure in connexion with research was allowed as a deduction from earmings, in accordance with the usual principle, but no allowance was made in respect of expenditure of a capital nature. Under my Budget proposals of last year, to which statutory effect has now been given, all research expenditure in connexion with any particular industrial undertaking is allowed as a deduction from earnings before assessment of tax. This applies to all expenditure on buildings, plant and equipment, and represents a clear departure from the hitherto sacred principle that untaxed income must not be used to produce additions to capital assets. The same principle is applied to contributions by industrial firms to research associations or universities for research. The value, and of course the.cost to the taxpayer, of such relief can be gathered from the contributions of this character which have already been made. For example, I.C.I. have given eighty fellowships at universities, of an average of $£ 600$ a year each, for research in physics and chemistry, and sciences derived therefrom, including engineering and chemotherapy. There are no restrictions or conditions attached to these fellowships. The Shell Group has made a gift of $£ 435,000$ to the University of Cambridge for a Department and chair of Chemical Fingineering, together with a yearly grant of $£ 2,500$ for scholarships, and Courtaulds have given $£ 118,000$ for a similar purpose to the Imperial College of Science and Technology. I do not doubt that, as time goes on, many other similar grants will be made, thus adding greatly to the funds available for fundamental research. Of the funds devoted by the Government to research in its own institutions, little more need be said except that experience goes to show that there are certain forms of fundamental research which it will probably be agreed can be only satisfactorily developed in this way. I mention, by way of illustration, the work to be carried on in the new Aeronautical Research Establishment at Luton, and the future of research into the uses of atomic energy.

There seems to be little doubt that the expenditure directly incurred by the Government on research will increase substantially as time goes on. I hope in the summary I have given I have succeeded in showing that, so far as financial aid is concerned, we now have a framework within which all that is required can be secured.

Organization. The efficient use of our resources, limited as they must be for a long time to come, demands the best possible organization. Without seeking to dogmatize in any way, I would suggest the following: (a) There should be recognized standards of remuneration. (b) Conditions of service should be such as to facilitate interchange between establishment and establishment, and between one type of service and another. A uniform pensions scheme, such as the Federated Universities Superannuation Scheme, should help to this end. (c) Free exchange of information and ideas should be en. couraged. (d) Without encouraging teaching institutions to undertake agency or contract work, research in applied science in such institutions should not be discouraged. (e) Similarly, the advantage of allowing a certain amount of fundamental research in industrial research establishments should be recognized. It should be remembered that it is to research, so conducted, that the discovery of the gas-filled lamp, which has meant an enormous annual saving in consumption of electricity, is due. ( $f$ ) To prevent wasteful overlapping, the various industrial associa. tions should establish special committees to discuss long-term programmes of research with representatives of the universities and the Government research organizations. In this connexion the question as to what fundamental researches can most profitably be conducted in Government establishments, or centrally in selected institutions, should be considered.

These are only suggestions which I hope may be thought worthy of further consideration; but, before leaving this part of the subject, in which my aim has been to indicate a number of questions which I think bodies such as the Manchester Joint Research Council might usefully explore, particularly in their regional aspects, it is right that I should say a word about the question of organization, so far as the arrangements of the central Government are concerned. I would unhesitatingly reject the suggestion, much canvassed of late, that there should be a Minister of Science. If we believe, as we must, that science enters into nearly every branch of human activity, there can be scarcely a Minister or a Department that is 
untrained students from the various forms of war service.

Finance. I come now to a matter which I would rank as high in importance as that of personnelfinance. Here I may modestly claim to have myself blazed a trail. Broadly speaking, research and development must be financed in one or more of the following ways : by industrialists, either in their own laboratories or through industrial research associations, or through grants to universities ard other scientific institutions; by universities and other scientific institutions out of their own resources; by Government, through research institutions of its own, or through grants to industrial research associations, to individual workers or to universities.

While I was still Lord President, the basis of grants to research associations was reviewed by the Advisory Council of the Department of Scientific and Industrial Research, under Lord Riverdale, and now arrangements have been made which represent a very substantial improvement on the old. Whereas the Department used to work on the principle that a Government grant would be available only until the association could be made self-supporting, the principle of a permanent grant is now accepted, and the basis of calculation has been liberalized. This marks a fundamental change in outlook. Government grants to universities are made through, and on the recommendation of, the University Grants Com. mittee, which has been reconstituted to bring it into closer touch with the universities. About a year ago, I met the Committee of Vice-Chancellors and foreshadowed a substantially increased rate of grant which has now been voted by Parliament for the current year. In addressing them, I referred, in particular, to the need for a revision of university salaries, and I made it clear that, for the first time this year and in future, capital expenditure would be taken into account in assessing grants. It is left to each university to allocate its grant as it thinks fit, subject, of course, to any general understanding between that university and the Committee. Grants earmarked for specific researches are made not by the Committee but by the Department of Scientific and Industrial Research, with the approval of the Treasury. The Department also administers a scheme of maintenance grants for postgraduate students to allow them to be trained in methods of research.

Expenditure by industrialists is assisted not by direct grant but by a system of tax relief. Up to this year, maintenance expenditure in connexion with research was allowed as a deduction from earmings, in accordance with the usual principle, but no allowance was made in respect of expenditure of a capital nature. Under my Budget proposals of last year, to which statutory effect has now been given, all research expenditure in connexion with any particular industrial undertaking is allowed as a deduction from earnings before assessment of tax. This applies to all expenditure on buildings, plant and equipment, and represents a clear departure from the hitherto sacred principle that untaxed income must not be used to produce additions to capital assets. The same principle is applied to contributions by industrial firms to research associations or universities for research. The value, and of course the.cost to the taxpayer, of such relief can be gathered from the contributions of this character which have already been made. For example, I.C.I. have given eighty fellowships at universities, of an average of $£ 600$ a year each, for research in physics and chemistry, and sciences derived therefrom, including engineering and chemotherapy. There are no restrictions or conditions attached to these fellowships. The Shell Group has made a gift of $£ 435,000$ to the University of Cambridge for a Department and chair of Chemical Fingineering, together with a yearly grant of $£ 2,500$ for scholarships, and Courtaulds have given $£ 118,000$ for a similar purpose to the Imperial College of Science and Technology. I do not doubt that, as time goes on, many other similar grants will be made, thus adding greatly to the funds available for fundamental research. Of the funds devoted by the Government to research in its own institutions, little more need be said except that experience goes to show that there are certain forms of fundamental research which it will probably be agreed can be only satisfactorily developed in this way. I mention, by way of illustration, the work to be carried on in the new Aeronautical Research Establishment at Luton, and the future of research into the uses of atomic energy.

There seems to be little doubt that the expenditure directly incurred by the Government on research will increase substantially as time goes on. I hope in the summary I have given I have succeeded in showing that, so far as financial aid is concerned, we now have a framework within which all that is required can be secured.

Organization. The efficient use of our resources, limited as they must be for a long time to come, demands the best possible organization. Without seeking to dogmatize in any way, I would suggest the following: (a) There should be recognized standards of remuneration. (b) Conditions of service should be such as to facilitate interchange between establishment and establishment, and between one type of service and another. A uniform pensions scheme, such as the Federated Universities Superannuation Scheme, should help to this end. (c) Free exchange of information and ideas should be en. couraged. (d) Without encouraging teaching institutions to undertake agency or contract work, research in applied science in such institutions should not be discouraged. (e) Similarly, the advantage of allowing a certain amount of fundamental research in industrial research establishments should be recognized. It should be remembered that it is to research, so conducted, that the discovery of the gas-filled lamp, which has meant an enormous annual saving in consumption of electricity, is due. ( $f$ ) To prevent wasteful overlapping, the various industrial associa. tions should establish special committees to discuss long-term programmes of research with representatives of the universities and the Government research organizations. In this connexion the question as to what fundamental researches can most profitably be conducted in Government establishments, or centrally in selected institutions, should be considered.

These are only suggestions which I hope may be thought worthy of further consideration; but, before leaving this part of the subject, in which my aim has been to indicate a number of questions which I think bodies such as the Manchester Joint Research Council might usefully explore, particularly in their regional aspects, it is right that I should say a word about the question of organization, so far as the arrangements of the central Government are concerned. I would unhesitatingly reject the suggestion, much canvassed of late, that there should be a Minister of Science. If we believe, as we must, that science enters into nearly every branch of human activity, there can be scarcely a Minister or a Department that is 
not interested in some way in the applications of science, and to add a super-Minister with general responsibilities and executive functions in relation to scionce could only lead to confusion. But that does not mean that I should be content with things as they are. We now have, in the Lord President, a Minister who is directly responsible for the general, as distinct from the departmental, scientific activities of the Government-the Department of Scientific and Industrial Research, the Medical Research Council, and the Agricultural Research Council. If a similar Council were set up for the social sciences, he would no doubt take that under his wing also. $\mathrm{H}_{e}$ has, during the War, been the channel of communication between the Scientific Advisory Committee and the Cabinet. I should like to see three changes made. First, I would have the Lord President formally recognized as the Minister responsible for dealing, on behalf of the Cabinet, and subject, where necessary, to reference to the Cabinet, with all general scientific questions in which the Government is concerned, including problems of organization, arrangements for Commonwealth or international conferences, and so forth. Secondly, I would continue the Scientific Advisory Cornmittee, which was a special war instrument, on a peace-time footing, with some extension of personnel, as the principal adviser of the Lord President and the Cabinet in scientifie matters. Thirdly, I would ereate a special section of the Cabinet secretariat, under an officer of appropriate qualifications and seniority, to assist the Lord President in the discharge of his new responsibilities. I believe, under arrangements such as these, the organization of the central Government would be suitably geared into the general complex of scientific organizations throughout the country.

Now I propose to say something about the position of our investigations into the use of atomic energy, and particularly about the prospects of industrial use. We have here a case where, as the result of a quite prodigious concentration of effort, such as could only have come about under the spur of war, results have been achieved in a few years which, in ordinary circumstances, would have taken perhaps ten times as long, or even longer. The work that has been done, of which I have some detailed knowledge, points clearly enough to certain lines of development in the future. I say nothing about the military problem. So far as industrial applications are concerned, it is quite certain that nothing has been discovered to justify the expectation that the energy released by an atomic explosion could be used directly as a source of industrial power, as, for example, the explosion of gases is used in an internal combustion engine, or a gas turbine, or in certain forms of rocket. The only method which existing knowledge suggests as practicable depends upon the conversion into heat of the energy released by a controlled process of nuclear fission. There is no difficulty in realizing this experimentally. But at the very outset practical troubles begin to arise. The first problem is to get the heat in a convertible form. This means a high temperature and involves very efficient controls and special measures to prevent corrosion of the metallic components and the rapid disintegration of the whole system.

The other major problem arises in connexion with the intense and very dangerous radiation by which the nuclear reaction is attended. This means elaborate shielding devices and a complete system of remote control. It would be absurd to suppose that these and other difficulties will not be overcome in time, and there is always the possibility of some fundamental new discovery completely changing the character of the problem; but the best opinion I can offer-and it is not based on my own conclusion but on the conclusions of those on whose judgment I can most confidently rely-is that it will be many years before nuclear energy comes on the market, for any but the most limited and specialized purposes, in competition with existing sources of power.

Nevertheless, the ultimate possibilities are such that it is clearly incumbent upon us as a nation to devote all the resources we can spare to further researches in this field. There will, I imagine, be little doubt that the Government must, for the time being at any rate, take a leading part in the organization of such researches. Nevertheless, I must stress the fact that these recent discoveries open up an onormous new field of scientific work, and should give tremendous impetus to research by physicists, chemists and engineers. Indeed, the matter goes much farther, for the devices that are employed to produce the new element plutonium provide a ready means of procuring a vast range of new radioactive substances, including radioactive forms of common elements used in medicine. For example, radiophosphorus, radio-iron, radio-sodium and many other substances can now be administered with the normal substance in proportions too small to be harmful, and their radioactive properties can be used to determine the exact behaviour of the particular therapeutic or nutrient agent in the human or animal organism. It does not require much knowledge, or much imagination, to realize what a revolution this may bring into medical science. In plant and animal physiology it may be equally important. There are also now available many alternatives to radium which may be both much less expensive and more manageable in radio-therapy. Thus, what may prove to be an uncovenanted benefit of inestimable value accrues to humanity as a by-product of the search for further means of destruction-proving again the truth of the saying that science often bestows her boons where no one planned.

\section{THE EDIBILITY OF BIRDS}

\author{
By DR. HUGH B. COTT \\ Department of Zoology, University of Cambridge
}

$I^{\mathrm{N}}$ T the autumn of 1941 I happened to be preparing some bird-skins at Beni Suef, Middle Egypt, when a casual observation led to what has proved a somewhat fruitful and little-explored line of inquiry. A palm dove (Streptopelia senegalensis) and a pied kingfisher (Ceryle rudis) had been skinned and the carcases thrown aside. Hornets were very plentiful in the garden where I was working and soon collected on the meat; but they were seen to concentrate their visits on one carcase, leaving the other almost neglected. Closer inspection showed that it was the dove that was receiving their attentions: with the kingfisher they would have little to do.

This apparent preference for one bird of the pair suggested further investigation, and it was decided to test the edibility of a wide range of birds, using Vespa orientalis as an indicator. Innumerable observations and experiments have hitherto been made 